\title{
Response Characteristics and Experimental Study of Underground Magnetic Resonance Sounding Using a Small-Coil Sensor
}

\author{
Shengwu Qin ${ }^{1, *}(\mathbb{D})$, Zhongjun Ma ${ }^{1}$, Chuandong Jiang ${ }^{2,3}$ (D), Jun Lin ${ }^{2,3}$, Yiguo Xue ${ }^{4}$, \\ Xinlei Shang ${ }^{2,3}$ and Zhiqiang $\mathrm{Li}^{4}$ \\ 1 College of Construction Engineering, Jilin University, Changchun 130026, China; \\ mzjgeology@gmail.com \\ 2 College of Institute of Instrument Science and Electrical Engineering, Jilin University, \\ Changchun 130026, China; chuandongjiang@gmail.com (C.J.); lin_jun@jlu.edu.cn (J.L.); \\ shangx107@mails.jlu.edu.cn (X.S.) \\ 3 Key Laboratory of Geophysics Exploration Equipment, Ministry of Education of China, \\ Changchun 130026, China \\ 4 Geotechnical and Structural Engineering Research Center, Shandong University, \\ Jinan 250061, China; xieagle@sdu.edu.cn (Y.X.); lzqhlxy@163.com (Z.L.) \\ * Correspondence: qinsw@jlu.edu.cn; Tel.: +86-135-0441-8387
}

Received: 23 August 2017; Accepted: 13 September 2017; Published: 15 September 2017

\begin{abstract}
Due to its unique sensitivity to hydrogen protons, magnetic resonance sounding (MRS) is the only geophysical method that directly detects water and can provide nondestructive information on subsurface aquifer properties. The relationship between the surface MRS signal and the location and characteristics of aquifers using large-coil (typically 50-150 m) sensors has been discussed based on forward modelling and experiments. However, few researchers have studied underground MRS using a small-coil sensor. In this paper, a parametric study and a large-scale physical model test were conducted to shed light on the critical response characteristics of underground MRS using a small-coil sensor. The effects of the size and number of turns of the transmitter coil and receiver coil, the geomagnetic declination, the geomagnetic inclination, and the position, thickness, and water content of a water-bearing structure on the performance of the underground MRS were studied based on numerical simulations. Furthermore, we derived the kernel function and underground MRS signal curves for a water-bearing structure model based on the simulations. Finally, a large-scale physical model test on underground MRS using a small-coil sensor was performed using a physical test system for geological prediction of tunnels at Shandong University. The results show that the inversion results of the physical model test were in good agreement with the physical prototype results. Using both numerical modeling and physical model tests, this study showed that underground MRS using a small-coil sensor can be used to predict water-bearing structures in underground engineering.
\end{abstract}

Keywords: magnetic resonance sounding; small-coil sensor; underground engineering; detection

\section{Introduction}

Magnetic resonance sounding (MRS) is the only active, non-invasive geophysical technique that provides information on the physical properties of water-bearing structures with an inherent selectivity to free hydrogen, and this technique has become an increasingly popular tool in hydro-geophysics [1-3]. Building on the idea of surface MRS proposed in an U.S. patent from the early 1960s [4], the work of Semenov and others in the 1970s, and the robust instruments designed and constructed in the 1980s by Russian scientists [5], the MRS method has been extensively developed over recent decades [6]. 
This method has been applied mainly, but not exclusively, to assessing the water content and aquifer parameters of primary aquifers.

Many research papers have presented extensive studies on surface MRS and its applications. Among the important contributions on this topic, the following studies have been particularly worthy of mention: Yaramanci et al. [7] obtained the geometry, water content, and hydraulic conductivity of an aquifer in a test at the Nauen/Berlin test site. Legchenko et al. [8] presented the basic principles of the MRS method based on numerical modelling and field examples. Wattanasen et al. [9] succeeded in detecting groundwater using MRS techniques in two areas in southern Sweden. Moreover, Cristina Pérez-Bielsa [10], Boucher [11], Chalikakis [12], and others have made outstanding contributions to the application of MRS in groundwater exploration.

The currently used MRS instruments, including Hydroscope [13], NUMIS [14], SNMR MINI [15], GMR [16], and JLMRS [17], use a circular wire coil with a diameter of $100 \mathrm{~m}$ positioned on the ground to excite and receive the MRS signal. When using a square coil configuration, the length of each side of the square is approximately $50-150 \mathrm{~m}$. Trushkin [18] used a coil with a figure-8 shape, which consisted of two connected coils, each with a diameter of $50 \mathrm{~m}$, to eliminate electromagnetic noise. The relationship between the surface nuclear magnetic resonance (NMR) signal and the location and characteristics of aquifers based on large-coil MRS sensors (typically with a coil diameter of 50-150 m) has been discussed based on forward modelling and experiments by Trushkin [18], Weichman [19] Yaramanci [7], Legchenko [20,21], Roy [2], Vouillamoz [22], Lehmann [23], and Hertrich [24]. However, due to the narrow space of underground engineering, it is impossible to use large-coil MRS sensors, and only small-coil MRS sensors can work in a narrow space. Currently, few scientists have addressed the use of small-coil MRS sensors (with a coil diameter of less than $10 \mathrm{~m}$ ) in underground engineering. The most recent articles have proposed the concept of effective inclination [1], which combines the geomagnetic inclination, declination, and coil angle. The MRS signal is associated with only the effective inclination in space, which simplifies the MRS signal calculations. However, an effective MRS signal cannot be obtained in a mine because of the high noise. Therefore, the authors concluded that the MRS method could not be applied underground. This investigation is the only study on small-coil MRS sensors in the literature.

The main objective of this research is to show how crucial parameters, such as (i) the sizes of the transmitter coil (Tx) and receiver coil (Rx), (ii) the number of turns of Tx and Rx, (iii) the geomagnetic declination and inclination, (iv) the position of the water-bearing structure, (v) the thickness of the water-bearing structure, and (vi) the water content of the water-bearing structure, influence the underground performance of small-coil MRS sensors. In addition, this research explores the response characteristics of underground MRS using a small-coil sensor through a parametric study and a large-scale physical model test. Furthermore, we derive the kernel function and underground MRS response curves of the water-bearing structure model based on the simulations. Finally, a large-scale physical model test is performed, and the results show that the inversion results of the physical model test are in good agreement with the results from the physical prototypes. Thus, underground MRS using a small-coil sensor can be used to predict water-bearing structures in underground engineering.

\section{Method and Principles}

The detailed principles of surface MRS are described in the literature [2,7,8,14,19-21,25], and the underground MRS method was developed based on the basic principle of surface MRS [26]. As shown in Figure 1, the coordinate system is defined as follows: $\vec{e}_{x}$ is the northern direction, $\vec{e}_{y}$ is the eastern direction, and $\vec{e}_{z}$ is the vertical direction, where down is positive. The direction of the geomagnetic field $\vec{B}_{0}$ is usually represented by the geomagnetic declination $D$ and inclination $I$. 


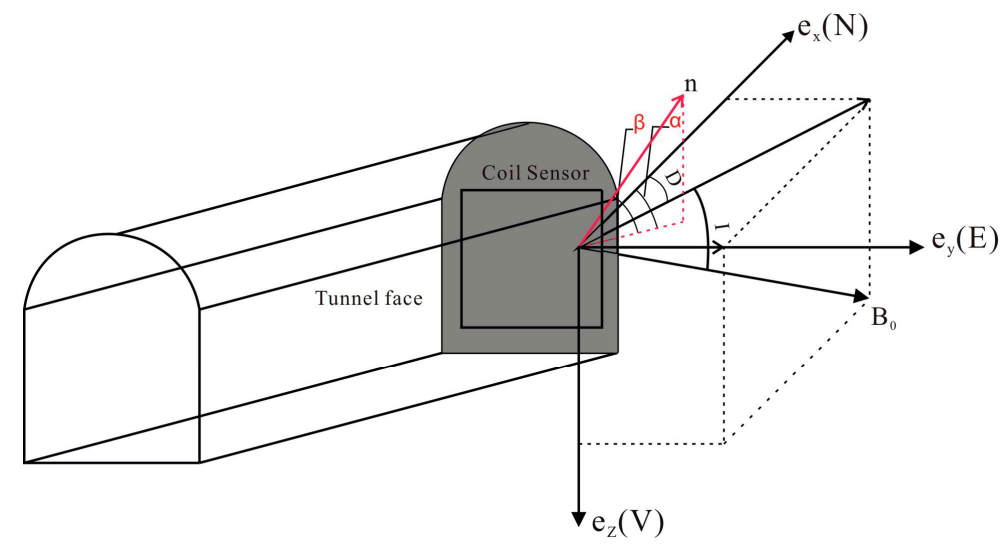

Figure 1. Schematic diagram of underground magnetic resonance sounding (MRS) excitation field and geomagnetic field.

$$
\vec{B}_{0}=\cos D \cos I \vec{e}_{x}+\sin D \cos I \vec{e}_{y}+\sin I \vec{e}_{z}
$$

Only the vertical component of the transmitting field $\vec{B}_{\mathrm{T}}^{\perp}$ affects the magnitude of the MRS response. When the coil sensor is laid out on the surface horizontally, the vertical component of the transmitting field $\vec{B}_{\mathrm{T}}^{\perp}$ is expressed as:

$$
\vec{B}_{\mathrm{T}}^{\perp}=B_{x}\left[\vec{e}_{x}-\left(\vec{e}_{x} \cdot \hat{b}_{0}\right)\right]+B_{y}\left[\vec{e}_{y}-\left(\vec{e}_{y} \cdot \hat{b}_{0}\right)\right]+B_{z}\left[\vec{e}_{z}-\left(\vec{e}_{z} \cdot \hat{b}_{0}\right)\right]
$$

where $B_{x}, B_{y}$, and $B_{z}$ are the components of the transmitting field $\vec{B}_{T}$ in the $x$ axis, $y$ axis, and $z$ axis directions, respectively. Then, $\vec{B}_{\mathrm{T}}^{\perp}$ is expressed as:

$$
\left(\vec{B}_{\mathrm{T}}^{\perp}\right)^{2}=\left(-\mathrm{s} D \cdot B_{x}+\mathrm{c} D \cdot B_{y}\right)^{2}+\left(-\mathrm{s} I \mathrm{c} D \cdot B_{x}-\mathrm{s} I \mathrm{~s} D \cdot B_{y}+\mathrm{s} D \cdot B_{z}\right)^{2}
$$

where s and c represent the sin and cos operators, respectively.

When the Tx and Rx are positioned at the tunnel face, this orientation can be characterized by two angles, $\alpha$ and $\beta$ :

$$
\vec{n}=\cos \beta\left(\cos \alpha \vec{e}_{x}+\sin \alpha \vec{e}_{y}\right)+\sin \beta \vec{e}_{z}
$$

where $\alpha$ is the deviation angle from the north toward the east, $0<\alpha<2 \pi$, and $\beta$ is the inclination angle from the horizontal plane downward, $0<\beta<\pi$.

At this point, the vertical component $\vec{B}_{\mathrm{T}}^{\perp}$ of the transmitting field at an arbitrary coil sensor position is represented as:

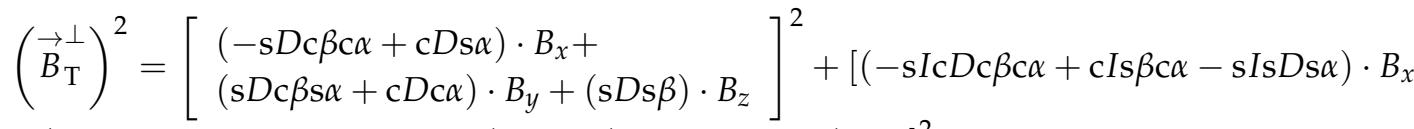

$$
\begin{aligned}
& \left.+(\operatorname{sIc} D \mathrm{c} \beta \mathrm{s} \alpha-\mathrm{cIs} \beta \mathrm{s} \alpha-\mathrm{s} I \mathrm{~s} D \mathrm{c} \alpha) \cdot B_{y}+(\operatorname{sIc} D \mathrm{~s} \beta+\mathrm{cIc} \beta) \cdot B_{z}\right]^{2}
\end{aligned}
$$

Underground, the coil sensor is positioned in the vertical direction. Then, the coil is energized by a pulse of alternating current $I(t)=I_{0} \cos \left(\omega_{0} t\right)$. The frequency of the current is equal to the Larmor frequency $f_{L}=\gamma B_{0} / 2 \pi$ of the protons in the geomagnetic field. Here, $\gamma=0.26752 \mathrm{~Hz} / \mathrm{nT}$ is the gyromagnetic ratio for free hydrogen protons, and $B_{0}$ is the geomagnetic field amplitude. Values for $B_{0}$ vary from $25,000 \mathrm{nT}$ near the equator to $65,000 \mathrm{nT}$ at high latitudes, resulting in Larmor frequencies of $0.9-3.0 \mathrm{kHz}$. After the pulse is terminated, the spins return to their equilibrium state. During this 
process, the spins emit an electromagnetic signal that is picked up by the Rx. The expression of the MRS signal is:

$$
E_{0}(q)=\int_{V} K_{3 D}(q ; \boldsymbol{r}) n(\boldsymbol{r}) d^{3} \boldsymbol{r}
$$

where $E_{0}$ is the initial amplitude of the MRS signal; $q=I_{0} \cdot \tau$ is the pulse moment, which is the product of the excitation current and excitation time; $n$ is the water content at point $r$ in space; and $K_{3 D}$ is the kernel function, which represents the sensitivity of the surface MRS signal at $r$ and is expressed by the following equation $[19,27]$ :

$$
\begin{aligned}
& K_{3 D}(q ; \boldsymbol{r})=-\omega_{\mathrm{L}} M_{0} \sin \left(\gamma_{\mathrm{p}} \frac{q}{I_{0}}\left|\overrightarrow{\boldsymbol{B}}_{\mathrm{T}}^{+}\right|\right) \times \frac{2}{I_{0}}\left|\overrightarrow{\boldsymbol{B}}_{\mathrm{R}}^{-}\right| \cdot e^{i\left(\varsigma_{T}+\varsigma_{R}\right)} \\
& \times\left[\hat{\boldsymbol{b}}_{\mathrm{R}} \cdot \hat{\boldsymbol{b}}_{\mathrm{T}}+i \hat{\boldsymbol{b}}_{0} \cdot\left(\hat{\boldsymbol{b}}_{\mathrm{R}} \times \hat{\boldsymbol{b}}_{\mathrm{T}}\right)\right]
\end{aligned}
$$

where $\omega_{L}$ is the Larmor frequency, $M_{0}$ is the net magnetization of the proton, $\gamma_{p}$ is the proton gyromagnetic ratio, $\overrightarrow{\boldsymbol{B}}_{\mathrm{T}}^{+}$is the counterclockwise component of the transmitting field with vertical component $\vec{B}_{\mathrm{T}}^{\perp}, \overrightarrow{\boldsymbol{B}}_{\mathrm{R}}^{-}$is the clockwise component of the receiving field with vertical component $\overrightarrow{\boldsymbol{B}}_{\mathrm{R}}^{\perp}$, and $\zeta_{\mathrm{T}}$ and $\zeta_{\mathrm{R}}$ are the phase components of the elliptical polarization field for transmitting and receiving, respectively. The unit vectors $\hat{\boldsymbol{b}}_{\mathrm{T}}, \hat{\boldsymbol{b}}_{\mathrm{R}}$, and $\hat{\boldsymbol{b}}_{0}$ are the direction vectors of the transmitting field, the receiving field and the geomagnetic field, respectively.

When the coil sensor layout is vertical, the normal direction is the $x$ axis. In this coordinate system, the tunnel axis is the $x$ axis, the excavation direction is the positive $x$ direction, and the location of the tunnel face is 0 . The MRS kernel function $K_{3 D}(q, r)$ should be integrated over the range of $(-\infty, \infty)$ on the $y$ axis and $z$ axis, separately, and then integrated over the range of $(-\infty, \infty)$ on the $x$ axis to calculate the MRS signal:

$$
\begin{gathered}
K_{1 D}(q, x)=\int_{-\infty}^{\infty} \int_{-\infty}^{\infty} K_{3 D}(q, x, y, z) d y d z \\
E_{0}(q)=\int_{-\infty}^{\infty} K_{1 D}(q, x) n(x) d x
\end{gathered}
$$

\section{Numerical Analysis of Underground MRS Using a Small-Coil Sensor}

The factors that influence the MRS signal include the electrical conductivity of the rock; the geomagnetic field; the geomagnetic inclination; the position; thickness and water content of water-bearing structures; and the electromagnetic noise, all of which are naturally occurring properties that have been discussed in many studies [28,29]. In addition, artificial technical factors, such as the shape, size, and number of turns of the detection coil; the maximum value and number of pulse moments; the detection sensitivity; and the inversion method also affect the MRS signal. As the amplitude of the MRS signal directly determines the detection distance, these artificial technical factors can be varied to achieve the optimal design for the coil sensor and instrument system. In addition, the MRS method can be adapted to the specific environments of mines and tunnels to achieve advanced detection of water.

\subsection{Calculation of the Kernel Function}

A numerical study has been conducted to explore the effects of the size and number of turns of Tx and Rx, the geomagnetic declination and the inclination on underground MRS performance. We assume that the resistivity of the surrounding rock is $500 \Omega \cdot \mathrm{m}$, that the Larmor frequency is $2300 \mathrm{~Hz}$, and that the coil sensor is positioned vertically in the north-south direction $\left(\alpha=0^{\circ}, \beta=0^{\circ}\right)$.

Figure 2 shows the three-dimensional slices of the kernel model results varying three different parameters. The three-dimensional coordinates are vertical distance, horizontal distance, and front depth, in meters. Figure $2 \mathrm{a}-\mathrm{d}$ clearly shows the forward kernel model results for coil diameters of 
$1 \mathrm{~m}, 2 \mathrm{~m}, 3 \mathrm{~m}$ and $4 \mathrm{~m}$, respectively. The detection depth increases with increasing coil diameter, and the asymmetry of the kernel model results decreases with decreasing coil diameter. In addition, the forward kernel models change irregularly because of the inhomogeneous magnetic field.

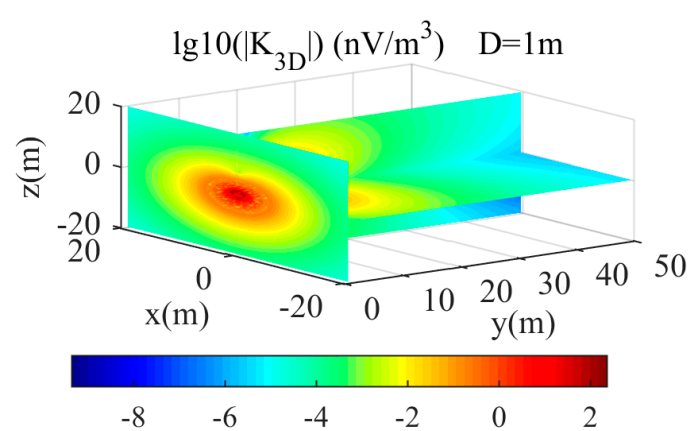

(a)

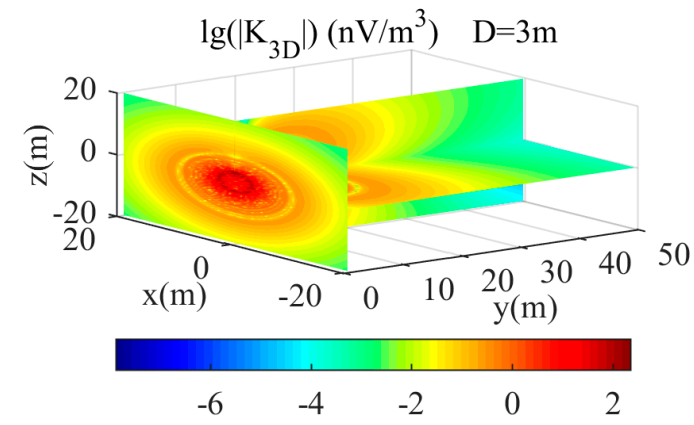

(c)

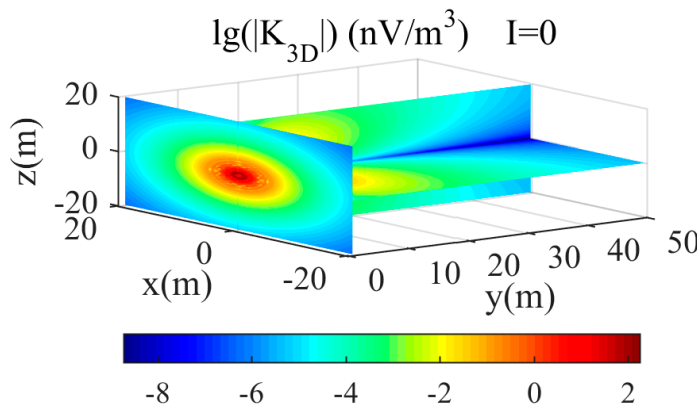

(e)

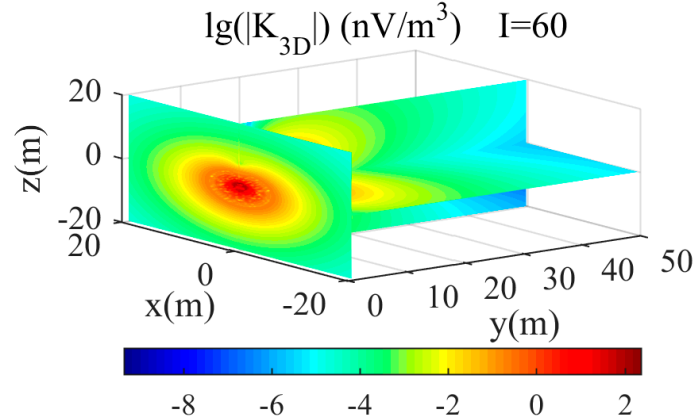

(g)

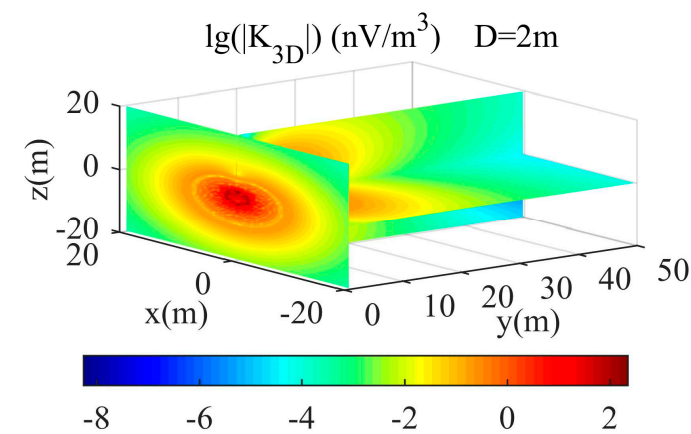

(b)

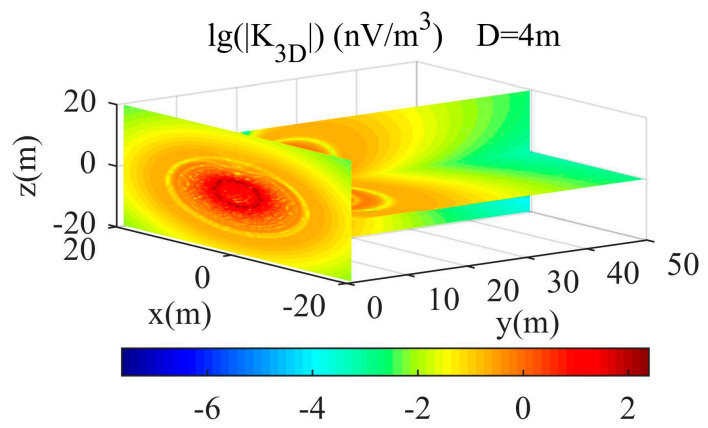

(d)

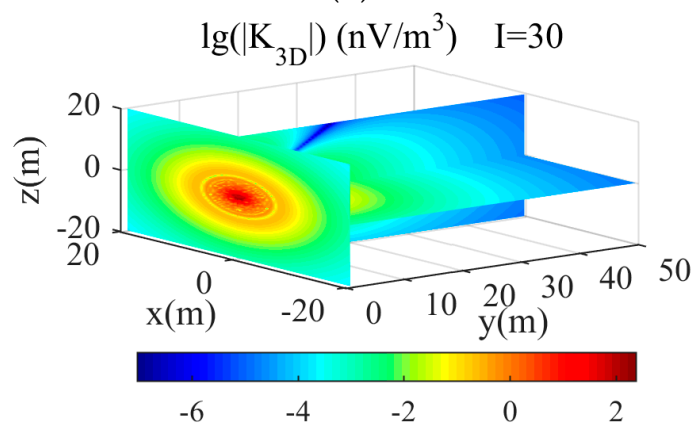

$(\mathbf{f})$

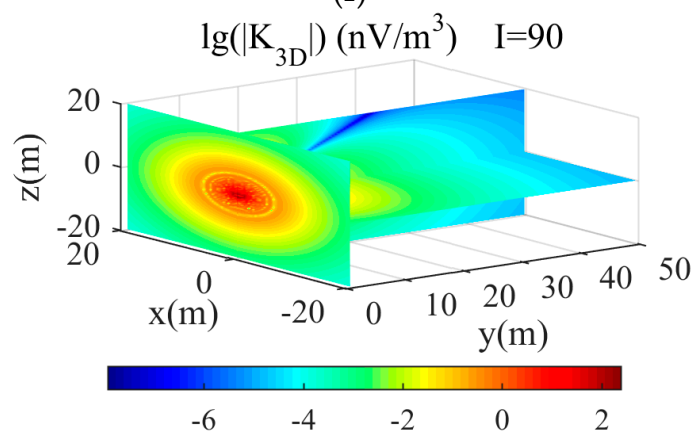

(h)

Figure 2. Cont. 


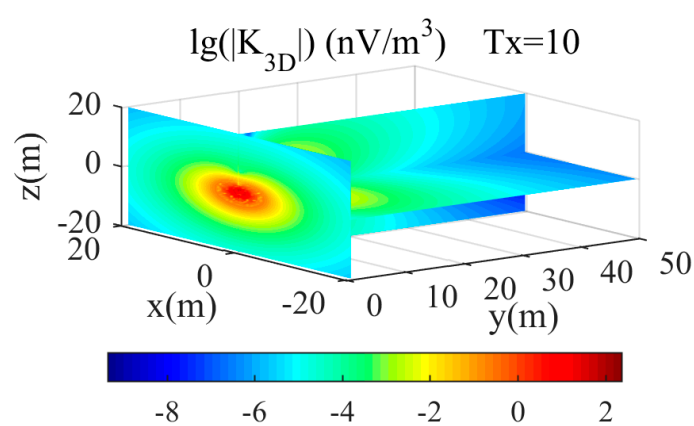

(i)

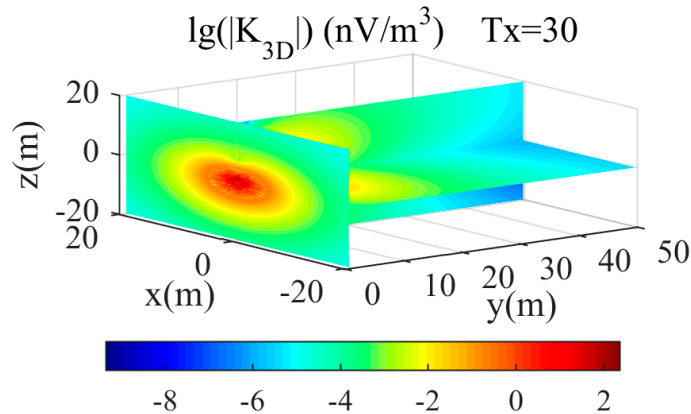

(k)

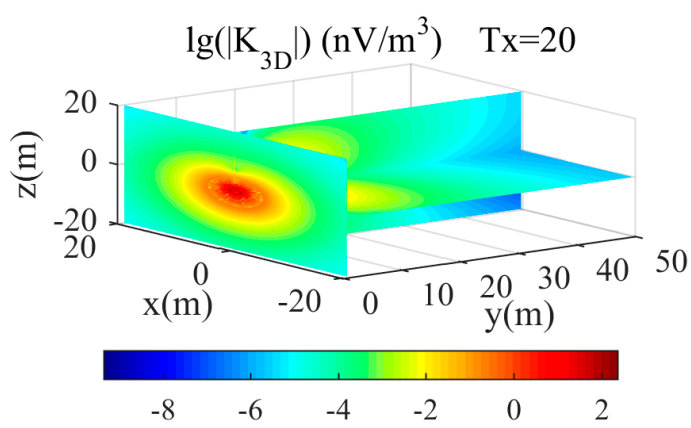

(j)

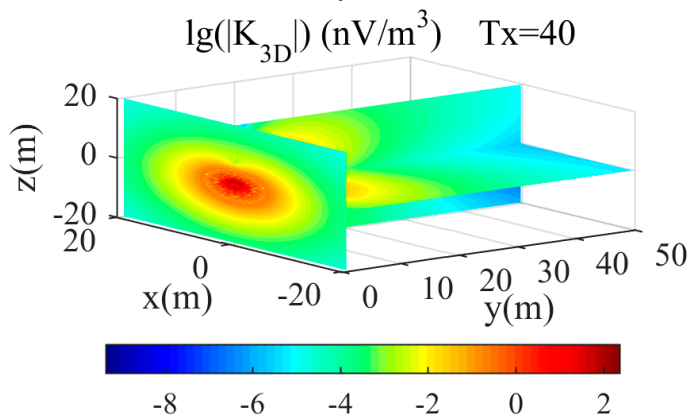

(1)

Figure 2. Three-dimensional slices of the kernel model results for underground MRS using a small-coil sensor. The Larmor frequency is $2300 \mathrm{~Hz}$, the resistivity of the surrounding rock is $500 \Omega \cdot \mathrm{m}$, and the coil is positioned vertically in the north-south direction $\left(\alpha=0^{\circ}, \beta=0^{\circ}\right)$. (a-d) Kernel model results for coil diameters of $1 \mathrm{~m}, 2 \mathrm{~m}, 3 \mathrm{~m}$, and $4 \mathrm{~m}$, respectively. 40 turns are assumed for Tx, and 128 turns are assumed for Rx; the geomagnetic inclination is $60^{\circ}$, and the geomagnetic declination is $0^{\circ}$. (e--h) Kernel model results using a 1-m diameter coil for geomagnetic inclinations of $0,30,60$, and $90^{\circ}$, respectively. 40 turns are assumed for Tx, and 128 turns are assumed for $\mathrm{Rx}$; the geomagnetic declination is $0^{\circ}$. (i-1) Kernel model results using a 1-m diameter coil for 10, 20, 30, and 40 coil turns for Tx, and 128 turns are assumed for $\mathrm{Rx}$, respectively. The geomagnetic inclination is $60^{\circ}$, and the geomagnetic declination is $0^{\circ}$.

Figure $2 \mathrm{e}-\mathrm{h}$ illustrates the forward kernel models for geomagnetic inclination angles of $0^{\circ}, 30^{\circ}$, $60^{\circ}$ and $90^{\circ}$, respectively. The results show that the asymmetry of the kernel remains constant as the geomagnetic inclination changes, indicating the important effect of the kernel on these parameters in the modeling process.

Figure $2 \mathrm{i}-1$ shows that the influence of varying the number of coil turns from 10 to 40 . The results clearly demonstrate that with an increasing number of coil turns, the asymmetry of the kernel forward models increases. When the number of coil turns is larger than 40 , the detection depth is more than $10 \mathrm{~m}$, i.e., the instrument can receive a valid MRS signal at $10 \mathrm{~m}$. Comparing Figures $2 \mathrm{a}-\mathrm{d}$ and $2 \mathrm{i}-1$, the forward modelling results of the two graphs show basically the same trend. Thus, increasing the size of the detection coil sensor and increasing the number of turns of the coil sensor improves the effective area of the detection coil.

\subsection{Underground MRS Response}

To perform an exploratory analysis on the response regularity and to understand the effects of the position, thickness and water content of water-bearing structures on underground MRS using a small-coil sensor, the following simulations were performed to simulate the MRS signal using Equations (5), (8) and (9). We modeled three groups of water-bearing geological structures ahead of the tunnel face with different positions, thicknesses and water contents based on the advanced detection theory of the underground MRS method, and we calculated the underground MRS signal 
curves. We assumed that the earth resistivity is $500 \Omega \cdot \mathrm{m}$, the Larmor frequency is $2300 \mathrm{~Hz}$, a 1-m diameter coil is positioned vertically in the north-south direction $\left(\alpha=0^{\circ}, \beta=0^{\circ}\right)$, Tx has 40 turns, Rx has 128 turns, the geomagnetic inclination is $60^{\circ}$ and the geomagnetic declination is $0^{\circ}$. For the first model, a water-bearing structure $2 \mathrm{~m}$ thick is located $5 \mathrm{~m}$ behind the coil with varying water content of $25 \%, 50 \%, 75 \%$, and $100 \%$. For the second model, a water-bearing structure $2 \mathrm{~m}$ thick is located $10 \mathrm{~m}$ behind the coil with varying water content of $25 \%, 50 \%, 75 \%$, and $100 \%$. For the third model, the water-bearing structure $1 \mathrm{~m}$ thick is located $10 \mathrm{~m}$ behind the coil with varying water content of $25 \%, 50 \%, 75 \%$, and $100 \%$.

The response regularity of the underground MRS is illustrated in Figure 3. As shown in Figure 3a,b, when the position of the water-bearing structure remains constant and the water content increases from $25 \%$ to $100 \%$, the amplitude of the $E_{0}-q$ curves for a 2-m-thick water body located $5 \mathrm{~m}$ ahead of the tunnel face increases from $14.43 \mathrm{nv}$ to $57.74 \mathrm{nv}$, and that for a 2-m-thick water-bearing structure $10 \mathrm{~m}$ ahead of the tunnel face increases from $10.67 \mathrm{nv}$ to $42.69 \mathrm{nv}$. In addition, the abscissa values corresponding to the peak value of the $E_{0}-q$ curve remains unchanged at 0.16 As and $0.48 \mathrm{As}$, respectively. Figure $3 \mathrm{c}$ shows the $E_{0}-q$ curves that were generated using a model with a 1-m-thick water-bearing structure located $10 \mathrm{~m}$ ahead of the tunnel face with varying water content of $25 \%, 50 \%$, $75 \%$, and $100 \%$. Figure $3 \mathrm{a}, \mathrm{b}$ clearly show that the $\mathrm{Q}$ value at the $E_{0}$ peak increases from 0.16 As to 0.48 as the depth of the water-bearing structure increases from $5 \mathrm{~m}$ to $10 \mathrm{~m}$ ahead of the tunnel face. Comparing Figure $3 \mathrm{~b}, \mathrm{c}$, the $\mathrm{Q}$ value at the $E_{0}$ peak remains unchanged, and the peak of the $E_{0}-q$ curve decreases with decreasing thickness of the water-bearing structure.

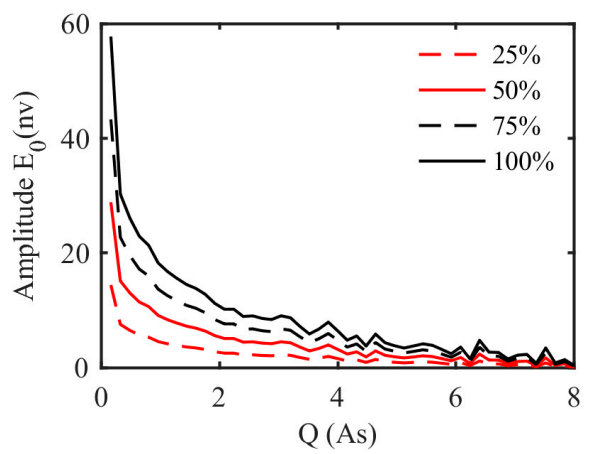

(a)

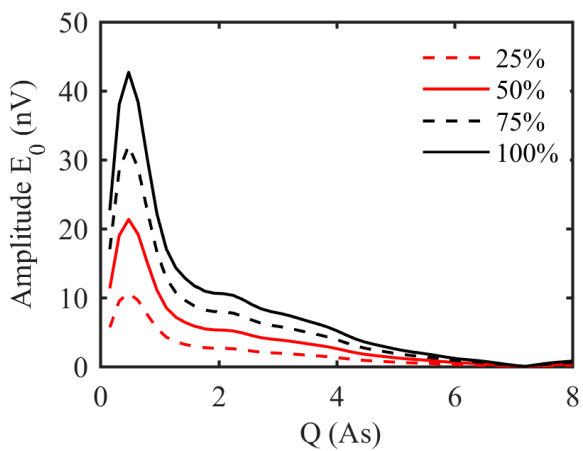

(b)

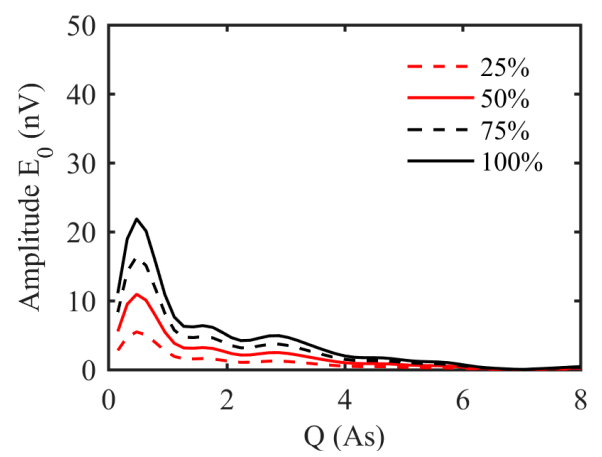

(c)

Figure 3. The underground MRS response $E_{0}-q$ curves from the forward model assuming a 1-m diameter coil, 40 turns for Tx and 128 turns for Rx. (a) a 2-m-thick water-bearing structure located $5 \mathrm{~m}$ ahead of the tunnel face with varying water content of $25 \%, 50 \%, 75 \%$, and $100 \%$; (b) a 2 -m-thick water-bearing structure located $10 \mathrm{~m}$ ahead of the tunnel face with varying water content of $25 \%, 50 \%$, $75 \%$, and $100 \%$; (c) a 1-m-thick water-bearing structure located $10 \mathrm{~m}$ ahead of the tunnel face with varying water content of $25 \%, 50 \%, 75 \%$, and $100 \%$. 
To explore the effects of the number of turns and the size of Tx and $\mathrm{Rx}$, the geomagnetic declination and the inclination on underground MRS using a small-coil sensor, we ran the following simulations to simulate the underground MRS signal using Equations (5), (8) and (9). We assumed a 2-m-thick water-bearing structure located $10 \mathrm{~m}$ ahead of the tunnel face with a water content of $100 \%$ and an earth resistivity of $500 \Omega \cdot \mathrm{m}$.

Figure 4 a shows the $E_{0}-q$ curves that were generated using a model of a 2-m-thick water-bearing structure located $10 \mathrm{~m}$ ahead of the tunnel face with a water content of $100 \%$ and 10, 20, 30, or 40 turns for Tx. As shown in the figure, gradually increasing the number of turns of Tx increases the maximum $E_{0}$ from 11.3 nvto $42.69 \mathrm{nv}$ and moves the wave crest of the $E_{0}-q$ curve to the left. Thus, when the radius of the coil is fixed and the number of turns increases, the excitation pulse moment needed to detect an aquifer of a certain depth can be decreased accordingly.

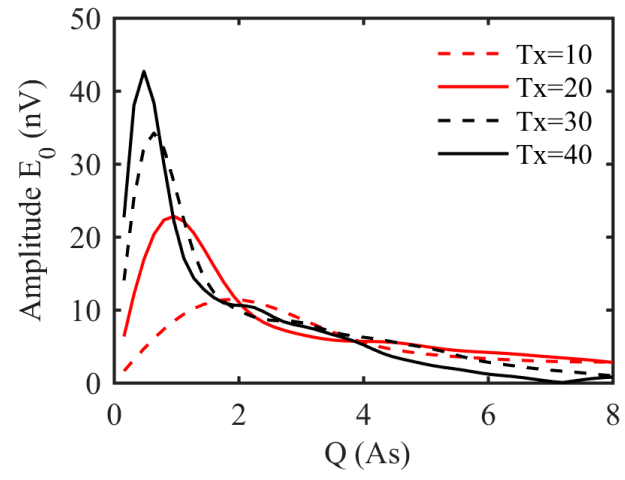

(a)

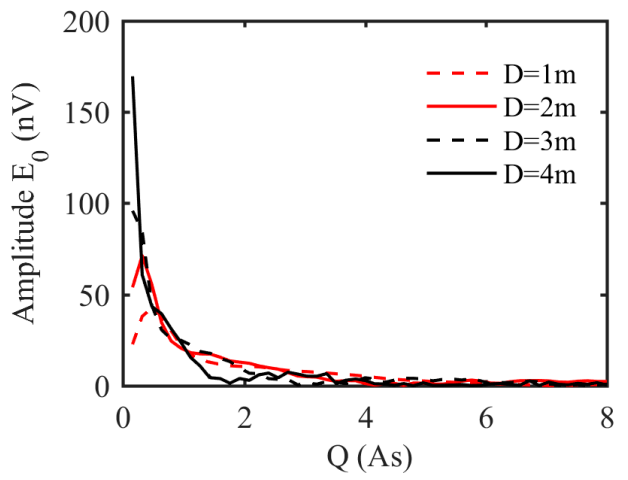

(b)

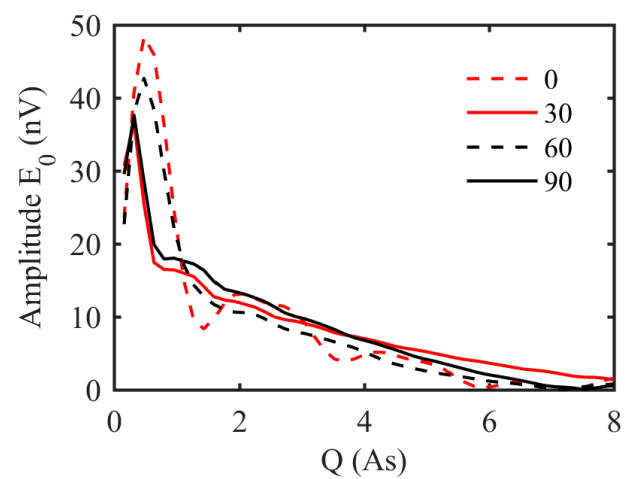

(c)

Figure 4. The underground MRS response $E_{0}-q$ curves from the forward model for a 2-m-thick water-bearing structure located $10 \mathrm{~m}$ ahead of the tunnel face with a water content of $100 \%$ (a) results assuming a 1-m-diameter coil; 128 turns for Rx; 10, 20, 30, or 40 turns for Tx; geomagnetic inclination of $60^{\circ}$; and geomagnetic declination of $0^{\circ}$; (b) results assuming 40 turns for Tx; 128 turns for Rx; coil diameter of $1,2,3$, or $4 \mathrm{~m}$; geomagnetic inclination of $60^{\circ}$; and geomagnetic declination of $0^{\circ}$; (c) results assuming a 1-m-diameter coil, 40 turns for Tx, 128 turns for Rx, and geomagnetic inclination of 0, 60, or $90^{\circ}$.

Figure $4 \mathrm{~b}$ shows the $E_{0}-q$ curves that were generated using a model of a 2-m-thick water-bearing structure located $10 \mathrm{~m}$ ahead of the tunnel face with a water content of $100 \%$ and a coil diameter of $1,2,3$, or $4 \mathrm{~m}$. As shown in the figure, as the coil diameter gradually increases, the maximum initial amplitude of the signal becomes larger and moves to the left in the direction in which the value decreases. Thus, as the diameter of the coil sensor increases, the excitation pulse needed to detect a water-bearing structure at a certain depth can be decreased accordingly.

Figure $4 \mathrm{c}$ shows the $E_{0}-q$ curves that were generated using a model for a 2-m-thick water-bearing structure located $10 \mathrm{~m}$ ahead of the tunnel face with a water content of $100 \%$ and a geomagnetic 
inclination of $0^{\circ}, 60^{\circ}$, or $90^{\circ}$. The curves clearly change with varying inclination, and the same results can be found in previous studies $[1,24]$. The maximum $E_{0}$ decreases with increasing inclination.

Next, simulations were run to explore the effect of the coil direction $(\alpha$ and $\beta)$ on underground MRS using a small-coil sensor. This model assumed a square coil with a side length of $2 \mathrm{~m}$ and 100 turns, a geomagnetic inclination of $I=60^{\circ}$ and a declination of $D=0^{\circ}$, and a variation in the normal direction of the coil $\left(\beta=-30^{\circ} \sim 60^{\circ}\right.$ and $\left.\alpha=0^{\circ} \sim 90^{\circ}\right)$. The maximum amplitudes of the MRS signal generated by a 1-m-thick aquifer with a water content of $100 \%$ located at a distance of $1 \mathrm{~m}$ to $30 \mathrm{~m}$ ahead of the tunnel face are calculated and presented in Figure 5. As $\beta$ increases from $-30^{\circ}$ to $60^{\circ}$, the maximum amplitude of the MRS signal from the aquifer within $10 \mathrm{~m}$ increases gradually. This result means that when the normal direction of the coil is parallel to the direction of the geomagnetic field, the MRS signal reaches its maximum value; in contrast, when they are perpendicular to each other, the MRS signal reaches its minimum value. However, for an aquifer located at a distance of greater than $10 \mathrm{~m}$, the opposite results are found, i.e., the value of the MRS signal reaches its maximum when the two directions are perpendicular and reaches its minimum when they are parallel. Moreover, as $\alpha$ changes from $0^{\circ}$ to $90^{\circ}$, the value of the MRS signal remains nearly constant, except for an aquifer located far away, where it is slightly larger when the geomagnetic field and the coil are perpendicular than when they are parallel. Therefore, the amplitude of the MRS signal can be improved by changing the coil direction. For a close aquifer, the coil should be positioned parallel to the geomagnetic field, while for a distant aquifer, the coil should be perpendicular.
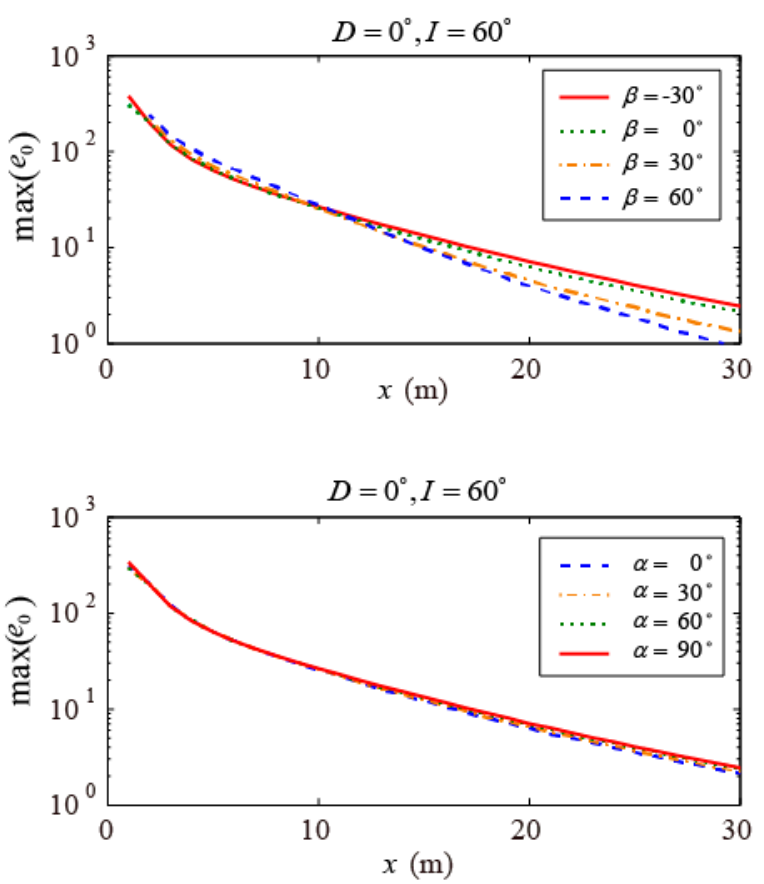

Figure 5. Maximum values of MRS signals with varying coil directions for a 1-m-thick aquifer with a water content of $100 \%$ located at varying distances

\section{Physical Model Test}

As a direct and quantitative advanced geophysical prediction method, the advanced prediction of underground MRS is an important reference for quantitatively predicting waterborne geological bodies in tunnels. The purpose of this experiment is to explore the relationship between the MRS signal and the water content of the water-bearing structure ahead of the tunnel face and to explore the feasibility of using a small-coil sensor in the advanced prediction of underground MRS. 


\subsection{Forward Model}

Prior to the physical model test, to explore the feasibility of underground MRS using a small-coil sensor, three groups of water-bearing geological models were established. The parameters of the hydrogeological models are shown in Table 1 , and the response $E_{0}-q$ curves were calculated and are shown in Figure 6. We assume the following parameters: earth resistivity of $500 \Omega \cdot \mathrm{m}$, Larmor frequency of $2300 \mathrm{~Hz}$, a square coil with a side length of $1 \mathrm{~m}$ placed vertically in the north-south direction $\left(\alpha=0^{\circ}, \beta=0^{\circ}\right), 40$ turns for Tx, 128 turns $\mathrm{Rx}$, geomagnetic inclination of $60^{\circ}$ and geomagnetic declination of $0^{\circ}$. As shown in Figure 6, the maximum $E_{0}$ increases from $10.81 \mathrm{nv}$ to $33.12 \mathrm{nv}$ as the water content increases from $25 \%$ to $100 \%$.

Table 1. Parameters of the theoretical models.

\begin{tabular}{cccc}
\hline Number & Aquifer Location (m) & Aquifer Thickness (m) & Water Content (\%) \\
\hline a & 3 & 1 & 25 \\
b & 3 & 1 & 50 \\
c & 3 & 1 & 100 \\
\hline
\end{tabular}

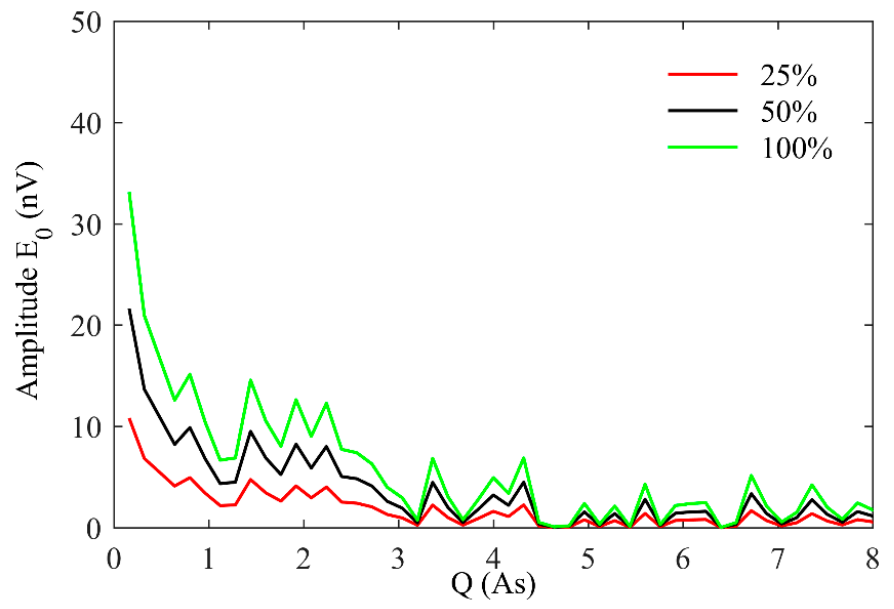

Figure 6. Underground MRS response curve of $E_{0}-q$ with varying water content of $25 \%, 50 \%$ and $100 \%$.

\subsection{Physical Model Test Analysis}

To simulate the underground MRS using a small-coil sensor in an actual project, an experiment was conducted using a large-scale experimental device. The tested system is based on the JLMRS instrument [17] and a small-coil sensor. A schematic diagram of the large physical model tests is shown in Figure 7. The large-scale integrated geophysical advanced detection model test device is $17 \mathrm{~m}$ long, $8.4 \mathrm{~m}$ wide, and $6.7 \mathrm{~m}$ high. The tunnel model is located in the middle of the large-scale model and is $2.0 \mathrm{~m}$ high, $1.7 \mathrm{~m}$ wide and $6 \mathrm{~m}$ long. To reduce the influence of the reinforcement and other factors on the test results, the tunnel cavity model is made of glass fiber-reinforced plastic materials, and clay is used as the filling material to represent the surrounding rock. The water-bearing geological structure device is placed $3 \mathrm{~m}$ ahead of the main tunnel model and has dimensions of $1.0 \mathrm{~m} \times 2.0 \mathrm{~m} \times 2.0 \mathrm{~m}$ (thickness $\times$ width $\times$ height), which is consistent with the cavities that often appear in tunnel construction. We used a square detection coil $(1 \mathrm{~m} \times 1 \mathrm{~m}$ with 40 turns for Tx and 128 turns for $\mathrm{Rx}$ ) to perform detections within the tunnel model. The water-bearing structure was gradually filled with water at water levels of $1 \mathrm{~m}, 1.5 \mathrm{~m}$, and $2 \mathrm{~m}$.

As shown in Figure 8, the water curves are obtained using the QT inversion method [30,31]. The results shown in Figure $8 \mathrm{c}$ are the underground MRS inversion results for water levels of $1 \mathrm{~m}$, $1.5 \mathrm{~m}$, and $2 \mathrm{~m}$, respectively. Thus, the relationship between the underground MRS signal and the water level is obtained. 
(1) The small-coil sensor used in underground MRS can receive valid MRS signals in the prediction experiment.

(2) As the water level increases from $1 \mathrm{~m}$ to $2 \mathrm{~m}$, the peak value of the water content curve increases from 0.18 to 1 . Thus, the underground MRS technique can effectively quantify the size of the water-bearing structure.

(3) The inversion results can accurately locate the aquifer, and the location and water content of the aquifer are consistent with the physical model, which confirms the validity of the prediction.
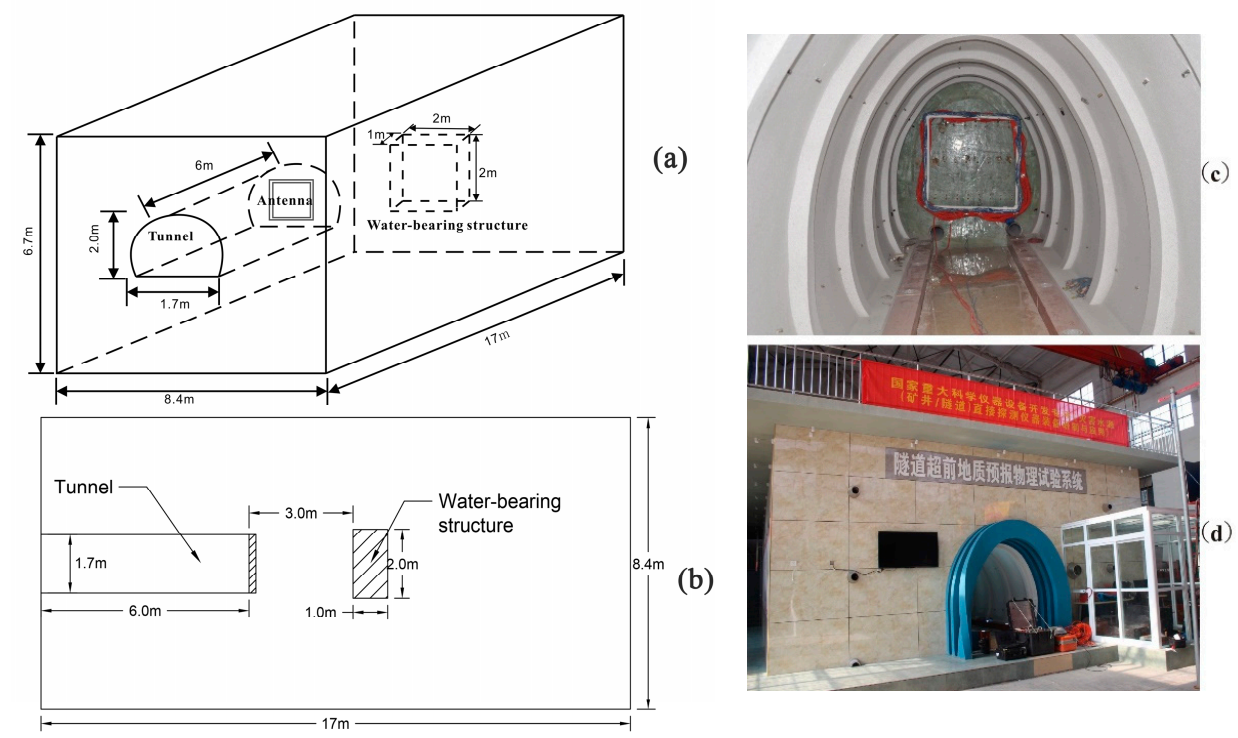

Figure 7. Diagram of the model tunnel and water-bearing structure. (a) 3-D diagram; (b) longitudinal profile of the test model; (c) small-coil sensor; (d) physical test system for geological prediction of tunnels.

(a)

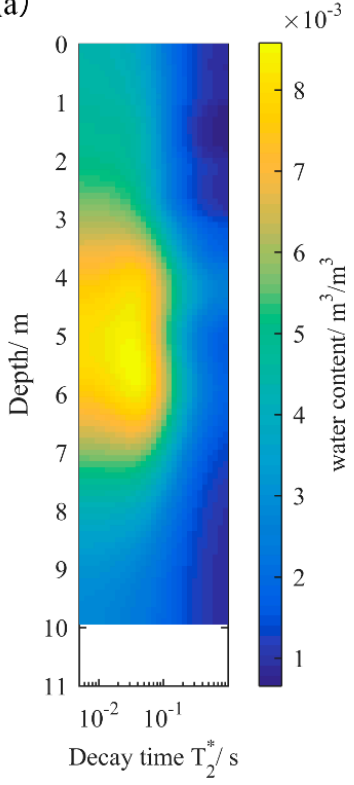

(b)

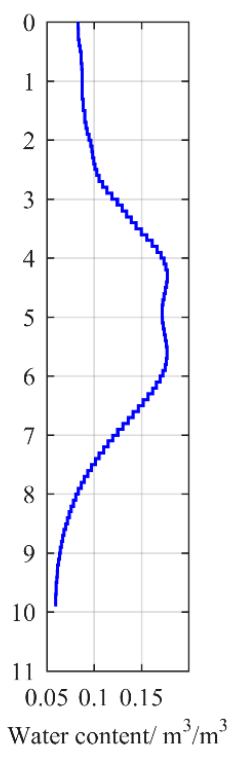

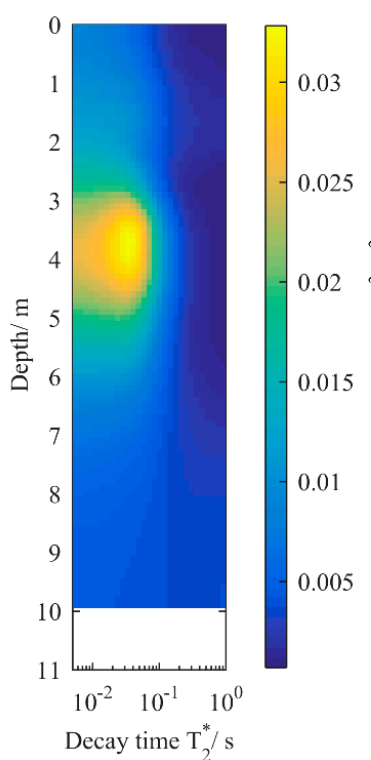

Figure 8. Cont. 
(c)
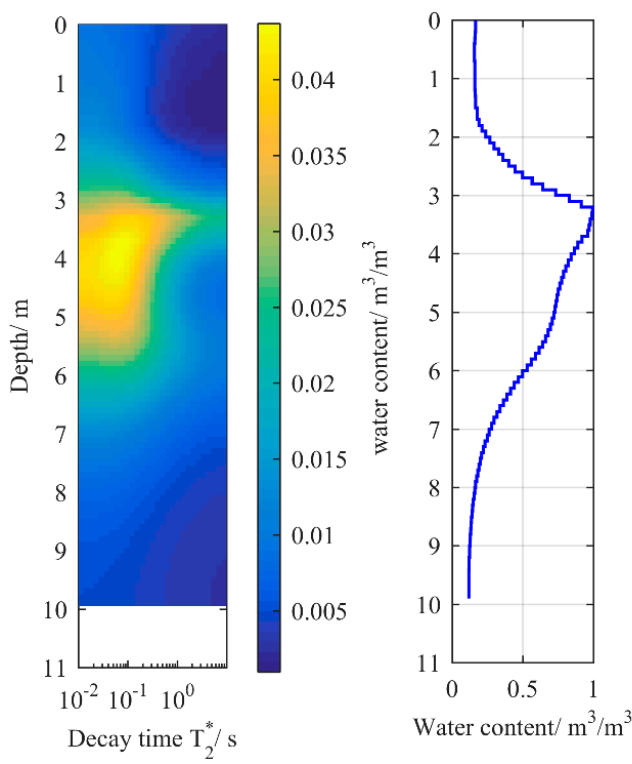

Figure 8. The inversion results of underground MRS. (a) inversion results for a water level of $1.0 \mathrm{~m}$; (b) inversion results for a water level of $1.5 \mathrm{~m}$; (c) inversion results for a water level of $2.0 \mathrm{~m}$.

\section{Conclusions}

For this study, experimental and numerical approaches are used to accurately analyze an underground MRS using a small-coil sensor. The factors that influence the MRS signal include the size and number of turns of $\mathrm{Tx}$ and $\mathrm{Rx}$; the geomagnetic declination; the geomagnetic inclination; and the position, thickness and water content of the water-bearing structure, all of which have been previously studied. The response characteristics of underground MRS using a small-coil sensor are obtained based on a parametric numerical study. The forward model results show that with increasing model depth, the amplitude decreases, and larger pulse moments are needed. With increasing water content and thickness of the water-bearing structure, the initial signal amplitude $E_{0}$ increases. We also conclude that the detection depth and the initial signal amplitude $E_{0}$ increase as the size and number of turns of the detection coil sensor increase, and both of these factors increase the effective detection area.

A large-scale physical model test using a small-coil sensor is performed using the test system for geological prediction of tunnels. The small-coil sensor successfully detected a valid MRS signal, and the inversion results of the physical model test are in good agreement with the physical prototype results, which verifies the feasibility and effectiveness of the predictions of underground MRS using a small-coil sensor. Using both numerical modeling and physical model tests, this study shows that underground MRS using a small-coil sensor can be used to predict water-bearing structures in underground engineering.

Acknowledgments: This work is supported by the National Major Scientific Instrument Development and Application Special Project (grant no. 2011YQ030133), the National Natural Science Foundation of China (grant nos. 51379112, 51422904 and 40902084), and the National Natural Science Foundation of China for Youths (grant nos. 41202197 and 41604083).

Author Contributions: All authors were responsible for different parts of this paper. S.Q. and Z.M. designed the experiments and wrote the whole paper; S.Q., Z.M., Y.X., and Z.L. performed the experiments; Z.M. and C.J. analyzed the data; X.S. designed the small-coil sensors; J.L. contributed to overall design of project and the revision of the manuscript.

Conflicts of Interest: The authors declare no conflict of interest. 


\section{References}

1. Greben, J.M.; Meyer, R.; Kimmie, Z. The underground application of Magnetic Resonance Soundings. J. Appl. Geophys. 2011, 75, 220-226. [CrossRef]

2. Roy, J.; Lubczynski, M. The magnetic resonance sounding technique and its use for groundwater investigations. Hydrogeol. J. 2003, 11, 455-465. [CrossRef]

3. Lin, J.; Du, G.; Zhang, J.; Yi, X.; Jiang, C.; Lin, T. Development of a Rigid One-Meter-Side and Cooled Coil Sensor at $77 \mathrm{~K}$ for Magnetic Resonance Sounding to Detect Subsurface Water Sources. Sensors 2017, 17, 1362. [CrossRef] [PubMed]

4. Varian, N. Ground Liquid Prospecting Method and Apparatus. U.S. Patent 3,019,383, 30 January 1962.

5. Semenov, A.G.; Schirov, M.D.; Legchenko, A.V.; Burshtein, A.I.; Pusep, A.Y. Device for Measuring the Parameters of an Underground Mineral Deposits. Great Britain, Patent 2198540B, 1989.

6. Hertrich, M.; Braun, M.; Gunther, T.; Green, A.G.; Yaramanci, U. Surface Nuclear Magnetic Resonance Tomography. IEEE Trans. Geosci. Remote Sens. 2007, 45, 3752-3759. [CrossRef]

7. Yaramanci, U.; Lange, G.; Hertrich, M. Aquifer characterisation using Surface NMR jointly with other geophysical techniques at the Nauen/Berlin test site. J. Appl. Geophys. 2002, 50, 47-65. [CrossRef]

8. Legchenko, A.; Baltassat, J.-M.; Beauce, A.; Bernard, J. Nuclear magnetic resonance as a geophysical tool for hydrogeologists. J. Appl. Geophys. 2002, 50, 21-46. [CrossRef]

9. Wattanasen, K.; Elming, S.- $\AA$. Direct and indirect methods for groundwater investigations: A case-study of MRS and VES in the southern part of Sweden. J. Appl. Geophys. 2008, 66, 104-117. [CrossRef]

10. Pérez-Bielsa, C.; Lambán, L.J.; Plata, J.L.; Rubio, F.M.; Soto, R. Characterization of a karstic aquifer using magnetic resonance sounding and electrical resistivity tomography: A case-study of Estaña Lakes (northern Spain). Hydrogeol. J. 2012, 20, 1045-1059. [CrossRef]

11. Boucher, M.; Favreau, G.; Vouillamoz, J.M.; Nazoumou, Y.; Legchenko, A. Estimating specific yield and transmissivity with magnetic resonance sounding in an unconfined sandstone aquifer (Niger). Hydrogeol. J. 2009, 17, 1805-1815. [CrossRef]

12. Chalikakis, K.; Nielsen, M.R.; Legchenko, A. MRS applicability for a study of glacial sedimentary aquifers in Central Jutland, Denmark. J. Appl. Geophys. 2008, 66, 176-187. [CrossRef]

13. Semenov, A. NMR Hydroscope for Water Prospecting. In Proceedings of the Seminar on Geotomography; Indian Geophysical Union: Hyderabad, Indian, 1987; pp. 66-67.

14. Vouillamoz, J.-M.; Descloitres, M.; Bernard, J.; Fourcassier, P.; Romagny, L. Application of integrated magnetic resonance sounding and resistivity methods for borehole implementation. A case study in Cambodia. J. Appl. Geophys. 2002, 50, 67-81. [CrossRef]

15. Hertrich, M.; Braun, M.; Yaramanci, U. Characteristics of MRS Soundings with separated loops. In Proceedings of the Near Surface 2004-10th EAGE European Meeting of Environmental and Engineering Geophysics, Urecht, The Netherlands, 6 September 2004.

16. Walsh, D.O. Multi-channel surface NMR instrumentation and software for $1 \mathrm{D} / 2 \mathrm{D}$ groundwater investigations. J. Appl. Geophys. 2008, 66, 140-150. [CrossRef]

17. Zhang, X. Development of the transmitter in a surface NMR water investigation instrument. Chin. J. Sci. Instrum. 2006, 27, 689-692.

18. Trushkin, D.V.; Shushakov, O.A.; Legchenko, A.V. The potential of a noise-reducing antenna for surface NMR groundwater surveys in the earth's magnetic field. Geophys. Prospect. 1994, 42, 855-862. [CrossRef]

19. Weichman, P.B.; Lavely, E.M.; Ritzwoller, M.H. Surface nuclear magnetic resonance imaging of large systems. Phys. Rev. Lett. 1999, 82, 4102-4105. [CrossRef]

20. Legchenko, A.; Valla, P. A review of the basic principles for proton magnetic resonance sounding measurements. J. Appl. Geophys. 2002, 50, 3-19. [CrossRef]

21. Legchenko, A.; Baltassat, J.M.; Bobachev, A.; Martin, C.; Robain, H.; Vouillamoz, J.M. Magnetic resonance sounding applied to aquifer characterization. Ground Water 2004, 42, 363-373. [CrossRef] [PubMed]

22. Vouillamoz, J.M.; Favreau, G.; Massuel, S.; Boucher, M.; Nazoumou, Y.; Legchenko, A. Contribution of magnetic resonance sounding to aquifer characterization and recharge estimate in semiarid Niger. J. Appl. Geophys. 2008, 64, 99-108. [CrossRef]

23. Lehmann-Horn, J.A.; Hertrich, M.; Greenhalgh, S.A.; Green, A.G. On the sensitivity of surface NMR in the presence of electrical conductivity anomalies. Geophys. J. Int. 2012, 189, 331-342. [CrossRef] 
24. Hertrich, M. Imaging of groundwater with nuclear magnetic resonance. Prog. Nucl. Magn. Reson. Spectrosc. 2008, 53, 227-248. [CrossRef]

25. Legchenko, A.; Descloitres, M.; Bost, A.; Ruiz, L.; Reddy, M.; Girard, J.-F.; Sekhar, M.; Kumar, M.S.M.; Braun, J.-J. Resolution of MRS applied to the characterization of hard-rock aquifers. Ground Water 2006, 44, 547-554. [CrossRef] [PubMed]

26. Lin, T.; Zhang, Y.; Wan, L.; Qu, Y.; Lin, J. A Para-Whole Space Model for Underground Magnetic Resonance Sounding Studies. IEEE J. Sel. Top. Appl. Earth Obs. Remote Sens. 2016, 9, 264-271. [CrossRef]

27. Weichman, P.B.; Lavely, E.M.; Ritzwoller, M.H. Theory of surface nuclear magnetic resonance with applications to geophysical imaging problems. Phys. Rev. E Stat. Phys. Plasmas Fluids Relat. Interdiscip. Top. 2000, 62, 1290-1312. [CrossRef]

28. Legchenko, A.; Shushakov, O.A. Inversion of surface NMR data. Geophysics 1998, 63, 75-84. [CrossRef]

29. Liu, D.-H.; Hu, X.-Y.; Li, Y. Understanding the effect of elliptical polarization in surface nuclear magnetic resonance method. Appl. Geophys. 2012, 9, 365-377. [CrossRef]

30. Mueller-Petke, M.; Yaramanci, U. QT inversion-Comprehensive use of the complete surface NMR data set. Geophysics 2010, 75, WA199-WA209. [CrossRef]

31. Müller-Petke, M.; Braun, M.; Hertrich, M.; Costabel, S.; Walbrecker, J. MRSmatlab-A software tool for processing, modeling, and inversion of magnetic resonance sounding data. Geophysics 2016, 81, 9-21. [CrossRef]

(C) 2017 by the authors. Licensee MDPI, Basel, Switzerland. This article is an open access article distributed under the terms and conditions of the Creative Commons Attribution (CC BY) license (http:/ / creativecommons.org/licenses/by/4.0/). 